\title{
Corpo mal-dito
}

\section{Considerações à margem da obra de Qorpo-Santo}

\author{
Ettore Finazzi-Agrò
}

Resumo: Lendo os textos de José Joaquim de Campos Leão, duas instâncias se apresentam como predominantes na sua escrita: por um lado, a urgência do testemunho e, pelo outro, a vontade de transgressão de qualquer gramática da representação. Balançando entre esses dois polos, Qorpo-Santo chega a nos dizer muito mais de que qualquer tratado histórico ou estudo sociológico sobre a sua condição de intelectual marginal e marginalizado e, mais em geral, sobre a situação cultural e humana vigente num Brasil periférico na segunda metade do século XIX.

Palavras-chave: Século XIX; Qorpo-Santo; Literatura e marginalidade

Résumé: A la lecture des textes de José Joaquim de Campos Leão, deux instances semblent gouverner son écriture : d'une part l'urgence du témoignage, d'autre part la volonté de transgresser toute règle grammaticale de la représentation. Balançant entre ces deux pôles, Qorpo-Santo nous en apprend bien plus que tout livre d'histoire ou toute étude sociologique sur la condition sociale d'un intellectuel marginal et marginalisé et, plus généralement, sur la condition humaine et culturelle des périphéries brésiliennes dans la deuxième moitié du xIx ${ }^{\text {eme }}$ siècle.

Abstract: Reading the texts by José Joaquim de Campos Leão, two instances emerge as predominant in his writings: on one side, the urgency of testimony, and, on the other, the will of transgressing any grammar of representation. Equating those two poles, Qorpo-Santo tells us much more than any historical treatise or sociological study about his condition of a marginal and marginalized intellectual, and, more generally, on the cultural and human situation of a peripheral Brazil in the second half of the 19th century. Keywords: 19th century; Qorpo-Santo; literature and marginality 
Brightness falls from the air, Queens have died young and fair,

Dust hath clos'd Helen's eye:

I am sick, I must die.

Lord, have mercy on us!

Thomas Nashe "Adieu, farewell Earth's Bliss"

Desapareçam da Terra

- Os que estão amaldiçoados!

Feitos seus depravados

- Os conduzam à tumba

Qorpo-Santo, "Cumpra-se"

É um hábito antigo da historiografia e da crítica literárias o de tentar ajustar obras e autores "irregulares" dentro de paradigmas hermenêuticos consolidados. Trata-se, no fundo, de buscar "normalizar" à força aquilo que aparentemente foge a qualquer tentativa de ser incluído dentro de um esquema discursivo, de um gênero literário ou de um estilo poético codificados. Toda história literária, toda leitura crítica procuram, com efeito, interpretar a exceção à luz de modelos normativos, de aparatos teóricos consolidados, visto que a possibilidade de entender o lugar, o tempo e a razão de ser de uma obra estão ligados à sua capacidade de veicular significados e significantes que sejam compatíveis com aquilo que já se sabe.

É singular, nesse sentido, que as propostas mais contundentes e mais fascinantes sobre a possibilidade de ler de forma antinormativa aquilo que foge ou tenta se subtrair ao cânone sejam contidas nos textos de duas aulas inaugurais lidas, por dois grandes filósofos e teóricos da literatura do século passado, ao ingressar numa das instituições mais antigas e prestigiosas do mundo como o Collège de France - que poderia ser considerado, dada a sua história plurissecular, um baluarte da tradição e da preservação acirrada da Norma. Refiro-me, evidentemente, às conferências de Michel Foucault e de Roland Barthes, proferidas, respectivamente, no dia 2 de dezembro de 1970 e no dia 
7 de janeiro de 1977. ${ }^{1}$ Atas solenes, então, nas quais os dois ilustres palestrantes enfrentam, justamente, a questão da "ordem discursiva", entendida no seu estatuto regulador e preceptivo, e colocam em pauta o problema de como avaliar aquilo que escapa ou tenta escapar às regras ditadas pelo poder e pelo cânone.

Descontadas as diferenças entre as perspectivas adotadas pelos dois ilustres teóricos, aquilo que sobressai é a tônica que ambos colocam sobre os modos, tanto no âmbito das disciplinas quanto naquele das práticas, de se furtar a uma ordem imposta, perscrutando e perlustrando os caminhos de uma palavra formalmente interdita - hors-pouvoir, como a define Barthes, ${ }^{2}$ ou colocada num lugar à parte, ou seja, num lugar onde se manifesta e atua o partage (ao mesmo tempo "partição" e "partilha") entre um discurso aceite e escutado e outro recusado e silenciado, na decisiva imagem armada sete anos antes de Roland Barthes por Michel Foucault. E é este último, aliás, que, a partir obviamente do seu estudo fundamental sobre a história da loucura na Idade Clássica, nos alerta sobre o fato de que a fronteira, invisível mas intransponível, entre a possibilidade de dizer e a sua interdição, passa necessariamente pela partição entre a razão e o seu oposto aparente - e isso se dá ainda hoje, numa modernidade que parece acolher e prestar escuta à palavra do louco:

Basta pensar em toda a armação de saber através da qual deciframos essa palavra; basta pensar em toda a rede de instituições que permite a alguém - médico, psicanalista -escutar essa palavra e que permite, ao mesmo tempo, ao doente vir trazer ou reter desesperadamente as suas pobres palavras; basta pensar em tudo isso para suspeitar que a partilha, longe de ser apagada, funciona de outra forma, seguindo linhas diferentes, através de novas instituições e com efeitos que já não são os mesmos. E embora o papel do médico não seja senão aquele de prestar ouvido a uma palavra finalmente livre, é sempre a partir da manutenção da cesura que se exerce a escuta. ${ }^{3}$

O filósofo francês, como se vê, aponta para a impossibilidade de sair de um esquema lógico imposto e normativo no acolhimento e na interpretação do discurso do Outro. E Barthes, depois dele, indica quais poderiam ser as respostas a essa tentativa de reduzir

1. M. Foucault. L'orde du discours. Paris, Gallimard, 1971; R. Barthes. Leçon. Paris, Seuil, 1978.

2. R. Barthes. Op. cit., p. 9.

3. M. Foucault. L'ordre du discours, ed. cit., p. 14-15 (trad. minha). 
o discurso - e, em particular, o discurso poético - à servidão de uma língua gregária, procurando capturar a exceção dentro de um paradigma hermenêutico compartilhado: para utilizar os seus termos, sentêter, se déplacer e jouer ("teimar", "deslocar-se" e "jogar" com os signos) - três maneiras complementares e/ou alternativas de se opor com força ao poder normativo do cânone, mantendo intacta a capacidade do escritor de inventar dentro de uma língua própria e inalienável ou de se furtar a um uso e abuso do discurso por ele inventado, escolhendo, no limite, abjurar o que se escreveu.

Chegando ao "estranho" caso de Qorpo-Santo, pseudônimo ou quase-heterônimo (visto que ele alude a si mesmo só na terceira pessoa) de Joaquim de Campos Leão, escritor insubmisso e marginalizado que viveu entre 1829 e 1883 numa Porto Alegre que no mínimo o ignorou mas que chegou também a expulsá-lo de todos os cargos públicos, podemos com facilidade aplicar a ele os postulados teóricos elaborados pelos dois grandes semiólogos e filósofos franceses quase um século depois. De fato, ele recusou desde o início, desde a grafia do seu nom de plume, a língua imposta pela norma, cavando, dentro dela, uma língua própria e ilegal que se reflete já no título da sua obra completa em nove volumes: Ensiqlopèdia ou seis mezes de huma enfermidade.

Obra, então, que desde o início se inscreve numa infração do discurso dominante e que se escreve no "fora" de uma lógica aparentemente destruidora de todas as disciplinas, de todos os paradigmas e de todos os dispositivos. De fato, na produção inúmera, na verdadeira avalanche escritural que Qorpo-Santo provocou e pela qual ele mesmo, na sua identidade autoral e humana, acabou sendo submergido aparecem textos de natureza mais variada: obras teatrais, poemas, crônicas, narrativas, cartas e relatos biográficos. Uma nebulosa ou uma constelação discursiva repleta de objetos diversos e de formas heterogêneas na qual é impossível encontrar um verdadeiro fio lógico que não seja justamente o desejo de dar espaço a uma proliferação incontrolada de palavras, de sons, de imagens. E é, com efeito, apenas seguindo a lógica do desejo, de um corpo atravessado e santificado pela vontade de dizer e de desdizer, de saber e de esquecer, que podemos - sem conseguir anular, porém, o partage - prestar ouvido, num silêncio também ele religioso, "sagrado" pela exposição indecorosa de um corpo, a esse discurso "investido pelo desejo, e que se julga a si mesmo - pela sua maior exaltação ou maior angústia - carregado de terríveis poderes". ${ }^{4}$

4. M. Foucault. Lorde du discours, ed. cit., p. 15. 
Basta, com efeito, ler os poemas religiosos ou devotos que Qorpo-Santo escreveu para se dar conta da verdadeira manía, no seu sentido pleno e originário, pela qual é crispada a sua inspiração e na qual instâncias físicas e sobressaltos místicos se cruzam e se sobrepõem numa prática que, justamente, santifica o corpo:

\author{
Louvado seja Deus! \\ Estou bebendo, \\ Estou escrevendo, \\ Estou eu lendo, \\ Estou fazendo! \\ Louvado seja Deus! \\ Estou chupando, \\ Estou ditando, \\ Estou narrando, \\ Estou matando \\ A sede - com mate \\ Que o estômago farte! 5
}

Baixo e alto, literatura e vida, espírito e carne aqui se misturam de forma inextricável, apontando para uma religião que é autenticamente religação entre instâncias opostas. E, mais uma vez, tudo se desenvolve e atua sob o signo de uma compulsão incontrolável a escrever, sem respeitar alguma norma imagética ou lugar comum lógico-linguístico.

Obra caótica, nesse sentido, a Ensiqlopèdia, expressão labiríntica e ininterrupta onde nenhuma partição - nenhuma partição e/ou partilha - deveria ser permitida, tirando aquelas que o próprio autor decidiu inserir e que todavia não definem, não fecham o discurso, mas, pelo contrário, o jogam fora dos seus confins. Os gêneros, os estilos, todo o aparato retórico e até linguístico parecem ser aqui colocados em questão ou revogados, numa ânsia expressiva que é certificada pelo frenesi na composição, pelo tempo diminuto em que o autor cumpriu a sua tarefa, deixou a sua mensagem tresloucada, compulso por uma obrigação de dizer, de "sentir tudo de todas as maneiras", para

5. "Sede”, in Qorpo-Santo. Poemas. Org. D. Espírito Santo. Rio de Janeiro, Contra Capa, 2006, p. 303-304. 
mencionar a ambição, também ela marcada pela húbris, de outro grande poeta irregular e marginalizado em vida como foi Fernando Pessoa ${ }^{6}$.

Seis meses de uma enfermidade, nessa perspectiva, cobrem - ou tentam encobrir - um tempo mais longo, uma doença mais ampla e profunda que evade e excetua os limites do tempo, os parâmetros da doença, para se espalhar numa época inteira de enfermidade, no espaço ilimitado de um discurso onde, para retomar as palavras de Barthes, "les crans d'arrêt et les verrous de sûreté ont sauté". É na região infinita da desrazão, é no tempo imenso de uma "razão em fogo", onde a obra se identifica com a sua ausência e com o seu vazio, que devemos colocar a produção obsessiva de QorpoSanto. Autor, então, que podemos considerar a testemunha alucinada de uma condição infeliz, denunciada através de uma linguagem que se expõe no seu retrair-se e no seu dobrar-se sobre si mesma; autor, enfim, que habita a história caindo todavia fora de qualquer lógica consequencial ou de qualquer comparação histórico-literária. Uma colocação, essa, que desmente ou inutiliza toda tentativa de confrontar os seus textos com aqueles, quase contemporâneos, de Bernardo Guimarães, Cardoso de Menezes e outros (entre os quais, talvez, Álvares de Azevedo), ou seja, com a produção goliardesca ou pantagruélica - assim definida e magistralmente estudada por Antonio Candido, como fenômeno em parte censurado da poesia romântica brasileira. ${ }^{9}$

Talvez o único nome que valeria a pena colocar ao lado de Qorpo-Santo seria o de Sousândrade, também ele poeta periférico e esquecido no Brasil do século XIX, se não fosse o fato de que na sua obra imensa e às vezes insensata podemos ainda encontrar (para usar uma expressão do autor mais amado por ele) "um método". Os outros, não: como seria, de fato, possível comparar os desvios momentâneos e os desmandos juvenis de uma poesia jocosa, com a produção inteira um autor que, ao longo de toda a sua existência, jogou os signos contra eles mesmos para produzir afinal apenas uma

6. Não por acaso, depois da manía, eu menciono aqui, em relação a Pessoa, a húbris: são termos que, junto com a alogía (i.e., a ausência de lógos), definem a esfera de um "descomedimento", de uma "desmesura" cujo sentido (sagrado), como aquele da loucura, foge à nossa razão e à nossa compreensão. Veja-se, para isso, ainda M. Foucault, "La folie, l'absence d'œuvre”, in M. F., Philosophie, Anthologie. Paris, Seuil, 2004, p. 130 e passim.

7. R. Barthes. Op. cit., p. 28 ("os breques e as travas de segurança arrebentaram”).

8. M. Foucault. "La folie, l'absence d'œuvre", cit., p. 127.

9. A. Candido. "A poesia pantagruélica". In: O discurso e a cidade. São Paulo, Duas Cidades, 1993, p. 225-44. 
obra ausente e uma ausência de obra? Só numa perspectiva crítica que leia apenas as dissonâncias as colocando numa lógica hermenêutica feita de dissimetrias e de hiatos seria possível, no meu entender, comparar esses autores incomparáveis (para parafrasear Marcel Detienne). ${ }^{10}$

E voltamos assim ao início, isto é, à tentativa evidente de normalizar, do ponto de vista da leitura, uma obra como a de Qorpo-Santo. Os exemplos dessa crítica procurando reconduzir aquela enchente discursiva, aquela multiplicação incontrolada de imagens no álveo de uma lógica histórica ou de um paradigma literário consolidado não faltam. Sobre os textos teatrais, por exemplo, se tem longamente debatido se eles poderiam ou deveriam ser filiados ao surrealismo ou ao teatro do absurdo, tornando o autor gaúcho um precursor - um tanto patético - , por um lado, de Jarry ou Ionesco e, pelo outro, de Breton ou Tristan Tzara. ${ }^{11}$ Se esse tipo de leitura pode ser compreensível no caso de Décio Pignatari ${ }^{12}$, que - na esteira dos irmãos Campos e, justamente, da sua re-visão de Sousândrade - sempre foi à procura de uma legitimação genealógica da exceção concretista, acho que seja difícil justificar esta tentativa de ler o anormal e o ab-norme que foi a produção de Qorpo-Santo à luz de uma norma literária que o legitime na sua exceção. Colocar, nesse sentido, o escritor dentro de um contexto discursivo conhecido pode atenuar ou até apagar o lado inquietante da sua escritura que é, ao contrário, o dado essencial da sua personalidade poética.

Nesse mesmo sentido vai, aliás, a escolha de normalizar a sua ortografia realizada por alguns dos editores dos seus textos, traindo assim, com toda a boa vontade e em perfeita boa fé, aquilo que resta um dos legados mais relevantes de Qorpo-Santo, ou seja, o culto à forma linguística e à ortografia entendidas não como armação do discurso - como forma do conteúdo, justamente - mas como objeto e alvo do próprio discurso - como conteúdo da forma, então, visto que os seus textos, para voltar ainda a Foucault, "enunciam no seu enunciado a língua na qual o enunciam". ${ }^{13}$ Aspecto, esse,

10. M. Detienne. Comparer l'incomparable, Paris, Seuil, 2000.

11. Veja-se, a esse respeito, o importante estudo de Eudinyr Fraga. Qorpo-Santo: Surrealismo ou Absurdo?. São Paulo, Perspectiva, s.d. [1988].

12. D. Pignatari. Contracomunicação. São Paulo, Perspectiva, 1971, p. 119-23.

13. M. Foucault, "La folie, l'absence d'œuvre", cit., p. 134. Veja-se, a esse respeito, a nota de Qorpo-Santo "Sobre a ortografia", incluída no volume 7 da sua Ensiqlopèdia, em que ele tenta explicar as suas escolhas gráficas, refletindo, no seu entender, a realidade fonética (Qorpo-Santo. Poemas, ed, cit., p. 373-73). 
que foi magistralmente sublinhado por Flora Süssekind ${ }^{14}$ - e para o qual já tinha apontado também Maria Valquíria Alves Marques $-{ }^{15}$, considerando como nas suas peças teatrais e nos poemas aparecem com frequência "cenas de escrita", ou seja, representações do sujeito escrevendo, onde a enunciação se dobra e se reflete em si mesma, como no caso do poema "Rapidez":

$$
\begin{aligned}
& \text { Corre a pena tão depressa } \\
& \text { - No papel } \\
& \text { Que eu não sei se é puro fel, } \\
& \text { Ou se mel } \\
& \text { O que nele escrevi, ou lancei! } \\
& \text { Eu lerei } \\
& \text { Quando acabar, então verei } \\
& \text { Se falei } \\
& \text { Com fel ou mel o que narrei! }{ }^{16}
\end{aligned}
$$

Essa questão da grafomania, essa compulsão doentia a escrever, aqui tematizada, mostra o quanto Qorpo-Santo tinha consciência do automatismo da sua composição e o quanto ele era ciente de que, naqueles versos, se escondia uma verdade a ser decifrada - decifrada, talvez, pelos outros, visto que ele confessava não ter o tempo e a paciência de reler os seus próprios escritos ("Nada me - custa a escrever; / Mas a rever - verso ou prosa, / - Fastidiosa coisa me - é!"). ${ }^{17}$

Nesse movimento frenético da caneta sobre o papel, de fato, nessa contínua ulterioridade do significante, o que contava, para ele, era mais uma vez a proliferação e a propagação dos signos em busca de um saber que ela tentava capturar na forma. Uma forma voluntariamente errada e por vezes alucinada, mas que ele achava que, no seu estranho sabor, podia talvez encerrar um saber escondido:

\footnotetext{
14. F. Süssekind, "Rola a tinta, e tudo finta!", in Qorpo-Santo. Poemas, ed. cit., p. 17-21.

15. M. V. Alves Marques. Escritos sobre um Qorpo. São Paulo, Annablume, p. 91-98 e passim.

16. Qorpo-Santo. Poemas, ed. cit., pp. 56.

17. Ibidem, p. 61.
} 
Se erro te parecer veres,

Em algum periodo leres,

- Não te atreves a emendar,

- Sem antes me ouvir explicar!

Pode bem ser que o sentido,

Com que o mesmo foi escrito,

Não seja por ti entendido,

Porém só sim - por mim sabido! ${ }^{18}$

Na verdade, ele nunca pôde nem quis realmente explicar os seus textos, que, com efeito, não acabam de fazer dobras na nossa lógica, não cessam de provocar e convocar a nossa identidade num conluio de discursos heterogêneos que têm a ver mais com a teimosia infantil de falar que com a censura adulta da razão e da norma.

Por isso acho que, embora altamente meritória, a edição das peças teatrais por parte de Guilhermino César ${ }^{19}$ ou aquela das poesias por parte de Denise Espírito Santo (que no sobrenome esteja escondida a fascinação pelo escritor gaúcho?) sejam tanto úteis quanto enganosas, no seu intuito de arrumar e emendar aquilo que se apresenta como um borrão ou um labirinto discursivo escrito de forma esquisita. No sentido da possível recuperação de uma ordem lógica vai, sobretudo, a escolha adotada para a publicação dos poemas, organizados do ponto de vista temático ("Bichos", "Comidas", "Mulheres extravagantes", etc.). No livro, todavia, são listados também argumentos como "Nonsense" ou "Enfermidades" que deveriam ser, na verdade, categorias de classificação e não textos classificados, criando, assim, uma espécie de heterotopia, pela qual aquilo que deveria representar o princípio, por assim dizer, "ordenador" e externo do discurso (o registro do nonsense ou os seis meses da enfermidade) é, de, fato, ordenado no interior do discurso.

Essa tentativa louvável de tornar "legível" (e "legítimo") o caos interno ao corpus poético acaba porém - e peço desculpa pelo jogo de palavras - por trair a letra maldita deixada pelo Qorpo e/ou que ele teimosamente diz mal. Escrita, com efeito,

18. Ibidem, p. 57-58.

19. Qorpo.Santo. Teatro Completo. Org. por G. César. Rio de Janeiro, SEAC/Funarte/snT, 1980. 
que se apresenta como voluntariamente irregular e anômica, marcada pela desordem, ou melhor, por uma ordem outra a ser mantida na sua natureza impulsiva e compulsiva, sendo trabalhada pelo desejo, sendo crispada pelo prazer ou pelo sofrimento momentâneos do Corpo. Frequentar ou habitar esse universo discursivo, em suma, significa tanto considerar que ele responde a outro paradigma quanto respeitar a sua disposição sintagmática, a sua prática na qual se reflete, de forma travessa ou oblíqua, não apenas a sua condição pessoal, mas a loucura recalcada do ambiente e do tempo em que ele vivia.

É claro que esse respeito pela confusão e pela sobreposição de assuntos diversos, essa manutenção da ordem dos textos e do nonsense na construção deles podem levar a uma leitura difícil ou até a uma incompreensão da letra, mas, em contrapartida, ele nos permite avaliar o discurso como um todo, nas suas articulações e nas suas ligações internas, nas suas passagens secretas e todavia necessárias, mantendo intacta a "santidade" que o distingue. Um grande intelectual gaúcho como Aníbal Damasceno Ferreira a quem devemos a re-descoberta das obras de Qorpo-Santo (que morreu em 13 de abril de 2013), encontrou, talvez, a definição mais contundente, na sua aparente simplicidade, sob a qual rotular esse discurso logicamente insensato. Ele afirmou, com efeito, numa entrevista que o único princípio que poderia reger esse conluio de falas heterogêneas deve ser ou é, de fato, o "singular":

Porque o singular, sob pena de o não ser, é, por excelência, o inconceituável - uma categoria à parte, que resvala às mais argutas especulações. ${ }^{20}$

E um pouco mais adiante, sempre no intuito de subtrair a obra de Qorpo-Santo a qualquer definição normativa, ele acrescenta:

Loucura? De jeito nenhum. Esta constrange, desaponta, choca. Vê-se, portanto, que qualquer definição seria nula rem. Demais, o sentido da singularidade está em si mesmo, acima das razões e das sem-razões. ${ }^{21}$

20. Janer Cristaldo, “Aníbal Damasceno Ferreira, um viajante à Xavier de Maistre”. In Travessia, v. 4, n. 7 (1984), p.12.

21. Ibidem, p. 13. 
Considerar singular aquilo que se apresenta atravessado pela pluralidade e pela proliferação, aparentemente incontrolada, das instâncias discursivas pode parecer um paradoxo, mas é, a meu ver, o paradoxo no qual encontramos, finalmente, o sentido possível da operação levada a cabo nos "seis meses de uma enfermidade" por Qorpo-Santo.

Apenas a suposição de uma "singularidade pura", ultrapassando a evidência da uma multiplicidade impura e de uma lógica multiforme, pode, nesse sentido, dar conta de um discurso aporético, ou seja, etimologicamente "sem passagens". Um discurso, então, que não aparenta ter nem entradas nem saídas, que não apresenta vias de fuga e que, todavia, permanece coerente na sua incoerência, aberto no seu fechamento sobre si mesmo, no seu dobrar-se e desdobrar-se sem limites. Um caráter singular, então, que se torna exemplar de uma lógica à parte, de uma condição partagée, onde nenhuma tentativa crítica pode penetrar, à qual nenhuma leitura normativa e tranquilizadora pode ter acesso. Porque qualquer exercício hermenêutico acabaria por apagar a santidade de um corpo maldito; porque tentar interpretar de forma racional um autor cujo nome era, no fundo, Legião, poderia se revelar um exorcismo da sua complexa unidade e da sua singularidade plural, que permanecem, ao contrário, a marca indelével e perturbadora da sua escrita.

Diante dessa impossibilidade de manter uma atitude crítica que, por um lado, exclua a loucura como explicação ou como atalho e, pelo outro, não utilize a razão como expediente para decifrar uma escrita que a ela não se submete, acho que a única possibilidade que resta é a de nos mover pelos limiares da obra, para tentar lançar uma luz sobre ela. E a margem, o "fora" que é "dentro" em relação ao texto, é constituído, a meu ver, pelo próprio nome que o assina: basta, com efeito, consultar o dicionário para descobrir que a palavra "corpo-santo", além de aludir à Igreja como conjunto de fiéis em Cristo (ainda uma identidade plural, então), indica em português - citando o Houaiss - o "clarão luminoso que, devido à eletricidade atmosférica, aparece nos mastros e em outra parte dos navios e que os marinheiros julgavam ser a representação do santo que os advogava”. Uma definição, esta, que remete para o fenômeno conhecido como "fogo-de-santelmo", tão presente nas crônicas portuguesas de navegação e de descoberta e que deve talvez ter fascinado, pelo seu caráter supersticioso e lendário, Campos Leão: a stultifera navis, a Narrenschiff na qual ele acaba por embarcar pode ser iluminada apenas por este fulgor momentâneo que, provindo do céu, fende a obscuridade da época e a noite da razão.

Descobri, aliás, há pouco tempo, que em italiano, além do mesmo significado presente em português, o termo corpi santi indica também, a partir da Idade Média, 
os bens ligados à igreja ou às ordens monásticas que se encontravam ao longo ou um pouco fora dos muros e das fortificações de uma cidade. Embora tudo isso seja o produto de uma conexão fantasiosa ou de uma pura coincidência semântica, acho que esta definição possa casualmente nos ajudar a compreender a "exceção" representada, na literatura brasileira do século XIX, por Qorpo-Santo. De fato, na sua natureza extravagante e na sua perturbadora presença, o escritor é, como os corpi santi italianos, algo que, no sentido latino do verbo excipere, é "tomado fora", é refém de um Poder, tanto religioso quanto civil, que o exclui no mesmo gesto com que o inclui numa ordem que o excetua, enfim, prendendo-o porém a uma lógica imprópria e normalizadora.

Justamente por isso a obra desse homem precário ou infame, ${ }^{22}$ vivendo ou sobrevivendo às margens da sociedade, da sua própria família e, talvez, de si mesmo, deve ser entendida na sua essência de documento poético que nos restitui uma existência singular atravessada pelas palavras, que nos devolve uma personalidade cindida e plural, rachada pelo desejo e pela vontade de dizer a sua verdade infantil e inaudita. Como um relâmpago ou como um corpo-santo, então, que abre uma fresta de luz na tempestade da sua e da nossa época.

Ettore Finazzi-Agrò é professor titular de Literatura Portuguesa e Brasileira no Departamento de Estudos Europeus, Americanos e Interculturais da Universidade de Roma "La Sapienza". Foi professor visitante em várias universidades portuguesas e brasileiras e publicou livros sobre Fernando Pessoa, Clarice Lispector e Guimarães Rosa, além de ensaios sobre Manuel Bandeira e Mário de Andrade, entre outros autores. Dirige as revistas Letterature d'America (Roma) e Rivista di Studi Portoghesi e Brasiliani (Pisa) e é membro de vários conselhos científicos.

22. O primeiro adjetivo se refere, obviamente, ao estudo magistral e pioneiro sobre a figura e a obra de Qorpo-Santo publicado por Flávio Aguiar no seu livro Os homens precários (Porto Alegre: A Nação/IEL/ DAC/SEC, 1975). O segundo para o famoso ensaio de Michel Foucault, "La vie des hommes infâmes" (in Dits et écrits. Paris: Gallimard, 1994, vol. III, pp. 237-55). 